\title{
Effect of Variations in Neck Position on Peak Expiratory Flow Rate in Supine Posture in Young Healthy Adults - A Cross Sectional Study
}

\author{
Sumedha Shamsunder Audi ${ }^{1}$, Susana Rasquinha Quadros ${ }^{2}$, Yogesh Parshuram Nerkar ${ }^{3}$ \\ ${ }^{1}$ Department of Physiology, Goa Medical College, Bambolim, Goa, India. ${ }^{2}$ Department of Physiology, Bambolim, \\ Goa Medical College, Bambolim, Goa, India. ${ }^{3}$ Department of Physiology, Goa Medical College, Goa, India.
}

\section{ABSTRACT}

\section{BACKGROUND}

Many individuals prefer using a pillow under their head when they sleep or read or use hand held electronic devices in recumbent position. Changes in position of the head with respect to the neck in supine posture may occur depending on the use of a pillow or height of the pillow used. This alteration of head and neck position might have an effect on pulmonary ventilation. The Peak Expiratory Flow Rate (PEFR) is one of the tests to assess pulmonary functions and PEFR can be performed easily and rapidly with the help of Wright's Mini Peak Flowmeter. This study was undertaken to see the effect of variations in neck position on peak expiratory flow rate in supine posture in young healthy adults.

\section{METHODS}

A cross sectional study was carried out on 150 apparently healthy medical students of both sexes in the age group of 18 - 21 years. PEFR values were recorded using Wright's Mini Peak Flow Meter. The subjects were asked to lie down in supine position on a wooden couch and recording of the peak expiratory flow rate was performed, initially by placing the subject's head directly on the wooden couch and then by keeping the head on a pillow of $5 \mathrm{~cm}$ height.

\section{RESULTS}

Data was analysed using paired ' $\mathrm{T}$ ' Test and the $\mathrm{p}$ value of less than 0.05 was considered as statistically significant. We found that the mean PEFR value obtained using a pillow of $5 \mathrm{~cm}$ height under the head was more than the mean PEFR value obtained without using the pillow and the change in mean PEFR values was statistically significant (Table 1).

\section{CONCLUSIONS}

After comparing the mean PEFR values in the supine position with and without use of a pillow, we found that mean PEFR value was significantly higher when PEFR test was performed with use of a low height pillow $(5 \mathrm{~cm})$ under the head. From the result of this study, we conclude that pulmonary ventilation is better when the head and neck are supported with a low height pillow in supine posture.

\section{KEY WORDS}

PEFR, Wright's Mini Peak Flow Meter, Supine Position, Pillow
Corresponding Author:

Dr. Sumedha S. Audi, Department of Physiology,

Goa Medical College,

Bambolim, Goa, India.

E-mail: audisumedha@gmail.com

DOI: $10.14260 / \mathrm{jemds} / 2020 / 610$

How to Cite This Article:

Audi SS, Quadros SR, Nerkar YP. Effect of variations in neck position on peak expiratory flow rate in supine posture in young healthy adults- a cross sectional study. J. Evolution Med. Dent. Sci. 2020;9(38):2801-2804, $10.14260 /$ jemds $/ 2020 / 610$

Submission 16-06-2020,

Peer Review 13-08-2020,

Acceptance 19-08-2020,

Published 21-09-2020.

Copyright (C) 2020 Sumedha Shamsunder Audi et al. This is an open access article distributed under Creative Commons Attribution License [Attribution 4.0 International (CC BY 4.0)] 


\section{BACKGROUND}

Many individuals feel comfortable when they use pillow under the head while lying down. Now a days a lot of time is spent by most of the people including students using hand held devices such as smart phones, tablets and very often these devices are used in lying down position. Use of a pillow of optimum height maintains normal stability of head and body. ${ }^{1}$ We wanted to study whether the pulmonary ventilation is better if a pillow of low height is used under the head or when pillow is not used in the supine position.

Different types of lung function tests are available to assess lung functions but some of these tests require costly equipment and also some tests involve complicated and lengthy procedures. Measurement of Peak expiratory flow rate is one of the tests to examine the ventilatory function of the lungs. The peak expiratory flow rate is readily measured with help of peak flow meters. The Wright's Mini Peak Flow Meter is widely used in doctor's clinics, hospitals and also at home by patients with airway diseases due to simplicity of the method of recording PEFR with help of this device. Peak flow meters are handy, affordable and can be easily carried due to its small size. The Peak expiratory flow rate tests measure functions of large airways and they assess active expiration.2,3

The Peak Expiratory Flow, expressed as litres/minute, is defined as the maximal speed of flow of air achieved during the maximal forced expiration initiated at full inspiration. ${ }^{4}$ During forced expiration, the rate of air flow is greatest in early part of expiration thus flow rises rapidly to a maximum value, peak expiratory flow and then decreases linearly over most of expiration as lung volume decreases. The initial part of the forced expiratory flow- volume curve depends on subject's effort hence he has to be motivated but expiratory flow rates later in expiration are independent of effort. ${ }^{5}$

Various researchers have done investigations on the influence of different postures on peak expiratory flow rate in healthy individuals using peak flow meters. The reports of some of these studies showed that the posture does not have much influence on the peak expiratory flow rate as their peak expiratory flow rate values did not change significantly on change in posture.6,7 Whereas results of few other studies indicated that the peak expiratory flow values change when posture changes from standing to sitting or to lying down.8,9,10 A study by Humayun Zafar and colleagues examined lung functions in healthy subjects by changing head and neck position in sitting posture and they found that change in position of head with respect to neck has influence on pulmonary ventilation in healthy subjects. ${ }^{11}$

In supine posture, change in position of head and neck can be achieved with help of a pillow under the head. High pillows often cause neck pain. A study by Zacharias Dimitriadis et al has indicated that chronic neck pain has adverse effect on ventilation and results in reduced lung capacity. They suggested that this may be due to decreased strength of neck muscles. ${ }^{12}$ In another study by Kyochul Seo et al, it was reported that lung capacity decreases with use of pillows having more height. They suggested that pillows of more height alter normal cervical spine curve resulting in decrease in airway space through which air flows into the larynx. ${ }^{1}$ Reiterer et al reported that hyperflexion of head and neck caused by high pillows can decrease flow of air due to excess flexion of the cervical spine. They stated that high pillows cause hyperflexion of head and neck resulting poor ventilation. ${ }^{13}$ However, there is scarcity of studies on the effect of changes in neck positions (mild flexion and mild extension of the head and neck) in supine posture on the peak expiratory flow rate in young healthy adults. Mild flexion of the head and neck can be achieved with use of low height pillow. If the head is kept directly on the bed without lifting the chin mild extension of the head and neck can be obtained.

Since use of high pillows has shown to cause adverse effect on the pulmonary ventilation, we wanted to see the effect of pillow of low height on ventilation in young healthy adults in the supine posture. Hence, we conducted this present study to see effect of variations in neck position on peak expiratory flow rate in supine posture in young healthy adults.

\section{METHODS}

The present cross-sectional study was carried out on 150 apparently healthy male and female medical students. The study population was of 18-21 years age group. The study was conducted in the Department of Physiology, Goa Medical College from $2 \mathrm{pm}$ to $5 \mathrm{pm}$. Informed consent was taken from each subject before starting the procedure.

The subjects chosen were not engaged in any type of regular athletic training, yoga or pranayama. Those subjects having history of allergy, upper and lower respiratory tract infections such as sinusitis, rhinitis, pharyngitis, laryngitis, bronchitis, chronic obstructive pulmonary diseases, taking medications, cigarette smoking, chest and spine deformities, chest or abdominal surgery were excluded from the study. From history and clinical examinations respiratory and cardiovascular diseases were ruled out. Anthropometric measurements were done. Height of the subject was measured without shoes using stadiometer and recorded to nearest 0.1 $\mathrm{cm}$. Weight was recorded with light clothes and without shoes on weighing scale and recorded to the nearest 100 grams. Body Mass Index (BMI) was calculated using formula, BMI = weight in kilograms $(\mathrm{Kg})$ divided by height in meter square $\left(\mathrm{m}^{2}\right)$. Normal range of BMI was taken as $18.5-22.9 \mathrm{~kg} / \mathrm{m}^{2}$ as per Indian guidelines. The subjects having normal body mass index were chosen for the present study. Underweight, overweight and obese subjects were excluded from the study.

Peak Expiratory Flow Rate was measured using Pulmopeak ${ }^{\mathrm{TM}}$ Peak Flow Meter (Figure 1) The measurable range of the peak flow meter was between $60 \mathrm{~L} / \mathrm{min}$ and 900 $\mathrm{L} / \mathrm{min}$. The scale increment on the device is by $10 \mathrm{~L} / \mathrm{min}$ so recording of PEFR value was done by rounding to the nearest tenth.

The subjects were briefed about the study protocol. Informed consent was obtained from them. After explaining the procedure in detail, they were demonstrated the method of using Wright's Mini Peak Flow Meter and were trained to use it correctly. Before starting the test, the subjects were asked to sit comfortably and relax for 5 minutes. Then they were told to lie on a wooden couch in supine posture with trunk straight, legs extended and their head straight without lifting chin. As per the experimental protocol, subjects were asked to inhale as deeply as possible, pinch the nostrils to prevent air from escaping through the nose and to perform forceful expiration in one single blow as fast, as hard and as 
complete as possible into the mouth piece of the Wright's Mini Peak Flow Meter. The subjects were instructed not to put tongue in front of the mouth piece and they were well trained to blow into the mouthpiece which was tightly sealed between teeth and lips so as to ensure that there was no air leak. If they sneezed or coughed during the experiment, they were told to start again. After each test care was taken to reset the pointer of the peak flow meter back to the starting point. The peak expiratory flow rate test was done 3 times with a rest period of 3 minutes between the tests and the highest reading of the 3 attempts was recorded and it was chosen for the statistical analysis. The subjects were allowed to rest for 10 minutes. Then again, the peak expiratory flow rate test was done with the subject lying in supine position with legs extended and the subject's head was kept on a pillow of 5-centimetre height. The same procedure was repeated three times with an interval of 3 minutes and the highest reading was recorded for analysing. The study was carried out over a period of 4 weeks.

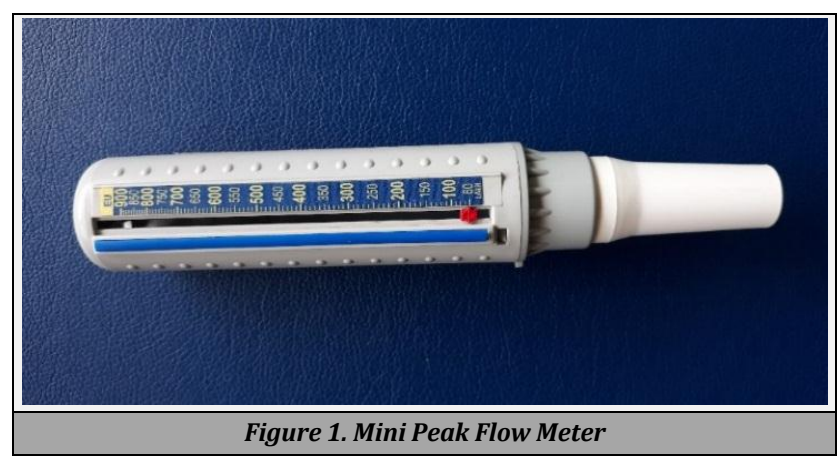

Statistical analysis was done using paired ' $\mathrm{T}$ ' Test and $\mathrm{P}$ value of less than 0.05 was accepted as indicating significant difference.

\section{RESULTS}

\begin{tabular}{|c|c|c|}
\hline Parameter & $\begin{array}{c}\text { Supine Position } \\
\text { with Pillow }\end{array}$ & $\begin{array}{c}\text { Supine Position } \\
\text { without Pillow }\end{array}$ \\
\hline Mean PEFR (L/min) & 393.4 & 384.2 \\
\hline SD & 103.28 & 102.07 \\
\hline $\mathrm{df}$ & \multicolumn{2}{|c|}{149} \\
\hline T value & $<.22$ \\
\hline P value & $<0.0001$ - statistically significant \\
\hline Table 1. Showing the Mean PEFR Value in L/min and SD in Supine \\
Position with Use of a Low Height Pillow Under the Head and \\
without Using Pillow \\
\hline
\end{tabular}

Data of 150 subjects was collected over a period of 4 weeks. The PEFR values in the supine position obtained with use of a low height head pillow and without use of a pillow, were analysed statistically using Microsoft Excel software. Statistical analysis was carried out using paired ' $\mathrm{T}$ ' test. P value of less than 0.05 was taken as statistically significant. Data is expressed in mean and standard deviation (SD). The mean PEFR value obtained with use of a pillow under the head was $393.4 \pm 103.28 \mathrm{~L} / \mathrm{min}$ and this value was higher than $384.2 \pm$ $102.07 \mathrm{~L} / \mathrm{min}$ which was the mean PEFR value obtained without use of a pillow. Paired ' $\mathrm{T}$ ' test revealed that there was a statistically significant change in the mean PEFR values $(\mathrm{p}<0.0001)$ (Refer Table 1 \& Figure 2.)

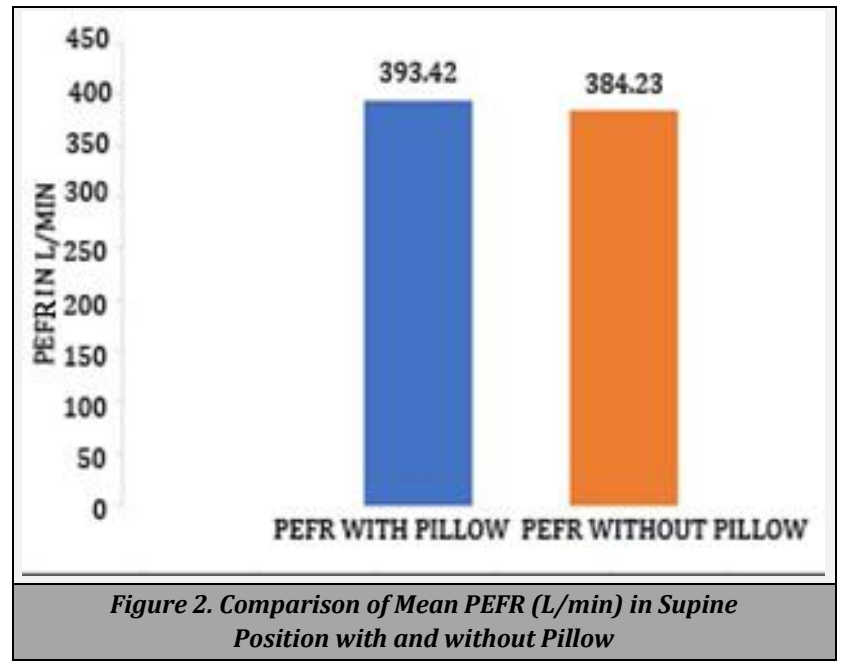

\section{DISCUSSION}

In our study, we found that mean peak expiratory flow rate value was higher in the supine position with a pillow of $5 \mathrm{~cm}$ height under the head, which causes the head and neck to be in mild flexion.

Better mean PEFR values obtained in our study with use of a pillow of lesser height $(5 \mathrm{~cm})$ could be due to the fact that it supports the head and neck for comfort and at the same time does not cause excessive bending (flexion) of the cervical spine. This possibly results in unhindered inflow and outflow of air through the upper airways.

Kyochul Seo and MiSuk Cho have examined lung volumes in supine position without pillow and also with use of pillow of $5 \mathrm{~cm}$ and $10 \mathrm{~cm}$ height. They reported that vital capacity was highest with use of pillow of $5 \mathrm{~cm}$ height. ${ }^{1}$ They found that the vital capacity decreases with use of pillows having more height $(10 \mathrm{~cm})$. They suggested that decrease in vital capacity obtained with $10 \mathrm{~cm}$ pillow was possibly due to excess flexion of curvature of the cervical spine. This results in decreased space in the upper airways through which air flows into the larynx. ${ }^{1}$ Best PEFR values can be obtained with maximum effort on the part of the subject. It involves deep inspiration and forceful expiration which requires optimal use of the accessory muscles of inspiration and expiration. A low height pillow of $5 \mathrm{~cm}$ under the head gives comfortable support to the head and neck in mild flexion and could probably help the subject to make the best use of these accessory muscles. This could be another reason for obtaining better PEFR values with the use of a low height pillow under the head.

In our study, we found that when the test was performed without use of the pillow under the head, the mean PEFR value obtained was lower. When pillow is not used, there is slight extension of the head and neck and this could possibly result in changes of tracheal dimensions. Various studies have shown that changes in length and diameter of the trachea occur on extension of the head and neck. Many researchers have examined the tracheal length on movement of the head and neck from flexion to extension. The results of their studies showed that there is increase in length of the trachea on extension of the head.14,15,16,17,18 A study by RS Harris reported that the diameter of the trachea decreased on extension of head and neck and this narrowing of the lumen was more 
pronounced during expiration. ${ }^{18} \mathrm{He}$ also reported that due to decrease diameter of the trachea that occurs when the head and neck is extended, there is increase in resistance to flow of air. ${ }^{19}$ A study by Richard Spann et al also suggested that changes in position of head relative to neck may have influence on upper airway resistance. ${ }^{20}$

Changes in the tracheal dimensions probably occur due to mild extension of head and neck when the pillow is not used. This could result in increased upper airway resistance resulting in decreased peak expiratory flow rate. Hence, in our study, lower mean PEFR value obtained when pillow was not used, could be due to increased resistance to air flow.

\section{CONCLUSIONS}

The mean PEFR value increased significantly when a low height head pillow was used, rather than when pillow was not used. Changes in the position of the head with respect to the neck in supine position has an influence on the peak expiratory flow rate in young healthy adults as seen in our study. The results of this study indicate that use of a low height pillow to support head in the supine posture may have a beneficial effect on the pulmonary function compared to lying down without a pillow.

Financial or Other Competing Interests: None.

\section{REFERENCES}

[1] Seo K, Cho M. Analysis of the pulmonary functions of normal adults according to pillow height. J Phys Ther Sci 2015;27(10):3085-7.

[2] Cloutier MM. Respiratory physiology. South Asia edition. Elsevier 2008: p. 61.

[3] Lumb AB. Nunn's applied respiratory physiology. $8^{\text {th }}$ edn. Elsevier 2017: p. 87.

[4] John NA. CC Chatterjee's human physiology. Vol. 1. 13 $3^{\text {th }}$ edn. CBS 2020: p. 333.

[5] Rhoades RA, Tanner GA. Medical physiology. $2^{\text {nd }}$ edn. Lippincott Williams \& Wilkins 2003: p. 331.

[6] Badaruddin M, Uddin MB, Khatun MF, et al. Study on peak expiratory flow rate in different positions. Dinajpur Med Col J 2010;3(1):17-8.
[7] Harshitha SH, Neelambikai N. Effect of posture on peak expiratory flowrate. TJPRC: International J Pharmacology and Physiology 2016;2(1):19-22.

[8] Wallace JL, George CM, Tolley EA, et al. Peak expiratory flow in bed? A comparison of 3 positions. Respir Care 2013;58(3):494-7.

[9] Yugesh K, Senthilkumar S. Effect of peak expiratory flowrate in different postures. Biomedicine 2013;33(3):182-6.

[10] Jyothi NS, Kumar GY. Effect of different postures on peak expiratory flow rate and peak inspiratory flow rate on healthy individuals. International J Physical Education, Sports and Health 2015;1(3):42-5.

[11] Zafer H, Albarrati A, Alghadir AH, et al. Effect of different head-neck postures on the respiratory function in healthy males. Bio Med Res Int 2018;4518269.

[12] Dimitriadis Z, Kapreli E, Strimpakos N, et al. Pulmonary function of patients with chronic neck pain: a spirometry study. Repir Care 2014;59(4):543-9.

[13] Reiterer F, Abbasi S, Bhutani VK. Influence of head-neck posture on airflow and pulmonary mechanics in preterm neonates. Pediatr Pulmonol 1994;17(3):149-54.

[14] Jordi Ritz EM, Von Ungern-Sternberg BS, Keller K, et al. The impact of head position on the cuff and tube tip position of preformed oral tracheal tubes in young children. Anaesthesia 2008;63(6):604-9.

[15] Agasti TK. Anaesthesia for postgraduates. $1^{\text {st }}$ edn. Jaypee Brothers Medical Publishers 2011: p. 17.

[16] Wong DT, Weng H, Lam E, et al. Lengthening of the trachea during neck extension: which part of trachea is stretched? Anesth Analg 2008;107(3):989-93.

[17] Toung TJ, Grayson R, Saklad J, et al. Movement of the distal end of endotracheal tube during flexion and extension of neck. Anesth Analg 1985;64(10):1030-2.

[18] Harris RS. The effect of extension of the head and neck upon the infrahyoid respiratory passage and the supraclavicular portion of the human trachea. Thorax 1959;14(2):176-80.

[19] Harris RS. Tracheal extension in respiration. Thorax 1959;14(3):201-10.

[20] Spann RW, Hyatt RE. Factors affecting upper airway resistance in conscious man. J Appl Physio 1971;31(5):708-12. 